\title{
Treatment of older patients with HER2-positive metastatic breast cancer with pertuzumab, trastuzumab, and docetaxel: subgroup analyses from a randomized, double-blind, placebo-controlled phase III trial (CLEOPATRA)
}

\author{
David Miles • José Baselga • Dino Amadori - Patrapim Sunpaweravong • \\ Vladimir Semiglazov • Adam Knott • Emma Clark · Graham Ross • \\ Sandra M. Swain
}

Received: 19 September 2013 / Accepted: 20 September 2013/Published online: 16 October 2013

(C) The Author(s) 2013. This article is published with open access at Springerlink.com

\begin{abstract}
Although the incidence of cancer increases with age, older patients are under-represented in cancer treatment trials, resulting in limited data availability in this patient population. Here we present results from pre-defined subgroup analyses conducted by age group ( $<65$ vs $\geq 65$ years) from a randomized, double-blind, placebo-controlled phase III trial in patients with HER2-positive metastatic breast cancer. Patients who had not received previous chemotherapy or biological therapy for HER2-positive locally recurrent, unresectable or metastatic breast cancer were randomly assigned to treatment with placebo, trastuzumab, and docetaxel or with pertuzumab, trastuzumab, and docetaxel. Primary endpoint was independently assessed progression-free survival. We performed pre-specified subgroup analyses of progression-free survival according to age. The study is registered with ClinicalTrials.gov, NCT00567190. 808 patients were enrolled. Of those, 127 patients were 65 years
\end{abstract}

Electronic supplementary material The online version of this article (doi:10.1007/s10549-013-2710-z) contains supplementary material, which is available to authorized users.

\section{Miles $(\square)$}

Mount Vernon Cancer Centre, Rickmansworth Road,

Northwood, Middlesex HA6 2RN, UK

e-mail: david.miles@doctors.org.uk

J. Baselga

Memorial Sloan-Kettering Cancer Center, Memorial Hospital, New York, NY, USA

D. Amadori

IRCCS Scientific Institute of Romagna for the Study and

Treatment of Cancer (IRST), Meldola, Italy

P. Sunpaweravong

Songklanagarind Hospital, Prince of Songkla University,

Hat Yai, Thailand of age or older (placebo arm: 67, pertuzumab arm: 60). Patients in both age groups experienced progression-free survival benefit with treatment in the pertuzumab arm ( $<65$ years: HR: $0.65 ; 95 \%$ CI $0.53-0.80 ; \geq 65$ years: HR: 0.52 ; $95 \%$ CI 0.31-0.86). Diarrhoea, fatigue, asthenia, decreased appetite, vomiting, and dysgeusia were reported more frequently in patients 65 years of age or older compared with younger patients. Neutropenia and febrile neutropenia were reported less frequently in the older age group. The efficacy and safety data reported in CLEOPATRA suggest that the combined use of pertuzumab, trastuzumab, and docetaxel should not be limited by patient age.

Keywords Elderly - HER2 - Metastatic breast cancer · Older women · Pertuzumab · Trastuzumab

\section{Introduction}

Cancer is an age-related disease and the probability of developing breast cancer is highest in women 70 years of

V. Semiglazov

NN Petrov Research Institute of Oncology, St Petersburg, Russia

A. Knott · E. Clark · G. Ross

Roche Products Limited, Welwyn Garden City, UK

S. M. Swain

Washington Cancer Institute, MedStar Washington Hospital

Center, Washington, DC, USA 
age or older [1]. Given the changing population demographics, the overall incidence of breast cancer will rise, driven by cancer diagnosed in older patients [2, 3], highlighting the importance of treatment guidelines for this patient population. In a US-based study Hutchins et al. [4] reported that although the estimated proportion of women $\geq 65$ years of age with breast cancer is $49 \%$, they only represent $9 \%$ of the patients participating in clinical trials. This discrepancy and the resulting scarcity of level I evidence leads to uncertainties about best practice in older patients, especially since older patients generally present with more comorbidities and related medications than younger patients [5-7], increasing the complexity of their management. Although survival rates of patients with breast cancer $\geq 65$ years of age in the US have increased over an observation period from 1977 to 2006 [8], several population-based studies have shown that older patients are frequently not treated according to standard of care [7, 9-11], with adverse consequences on survival outcomes $[12,13]$. Results from a prospective, observational US-based study in patients with HER2-positive metastatic breast cancer showed that elderly patients present with higher rates of underlying cardiovascular disease and are less likely to receive cytotoxic anti-cancer therapies compared with younger patients [14]. Trastuzumab-based treatment resulted in a survival benefit in all age groups compared with trastuzumab-free therapy [14]. Similarly, in HER2-positive early breast cancer, trastuzumab-based therapy significantly improved disease-free [15] and overall survival [16] compared with chemotherapy alone. In an exploratory analysis from the same study, age ( $\leq 40$ vs $>40$ years) was not significantly associated with disease-free or overall survival, either in the trastuzumab arm or in the observation arm [17]. This analysis was limited by a relatively short median follow-up of 2 years, which was chosen to avoid bias introduced by cross-over to the trastuzumab arm [17].

We performed a randomized, double-blind, placebocontrolled phase III study to investigate the efficacy and safety of pertuzumab, trastuzumab, and docetaxel compared with placebo, trastuzumab, and docetaxel in patients with HER2-positive first-line metastatic breast cancer. Progression-free survival was significantly improved with pertuzumab, trastuzumab, and docetaxel [18], and this combination was first approved in June 2012 by the US FDA for first-line treatment of HER2-positive metastatic breast cancer. After one additional year of follow-up, the overall survival benefit with pertuzumab, trastuzumab, and docetaxel had reached statistical significance, demonstrating a clinically meaningful improvement compared with trastuzumab and docetaxel [19]. In CLEOPATRA, $16 \%$ $(n=127)$ of patients were 65 years of age or older. Here we report efficacy and safety analyses in older patients compared with those in patients $<65$ years of age.

\section{Methods}

Study design and treatment

Study details have been published previously [18, 19]. CLEOPATRA was a randomized, double-blind, placebocontrolled phase III trial designed with two treatment arms: placebo, trastuzumab $\left(\right.$ Herceptin $^{\circledR}$, F. Hoffmann-La Roche, Basel, Switzerland) and docetaxel (Taxotere ${ }^{\circledR}$, SanofiAventis, Paris, France) (referred to as placebo arm); and pertuzumab (Perjeta ${ }^{\circledR}$, F. Hoffmann-La Roche), trastuzumab and docetaxel (referred to as pertuzumab arm). Primary endpoint was progression-free survival, defined as the time from randomization to disease progression, confirmed by an independent review facility according to Response Evaluation Criteria in Solid Tumors (RECIST) [20] or death from any cause within 18 weeks of the patient's last tumour assessment. Secondary endpoints included overall survival, progression-free survival by investigator assessment, objective response rate and safety. All study drugs were administered intravenously during a 3 -weekly cycle. Pertuzumab/placebo was given at $840 \mathrm{mg}$ in cycle 1 , followed by $420 \mathrm{mg}$ in every subsequent cycle. Trastuzumab loading dose was $8 \mathrm{mg} / \mathrm{kg}$ in cycle 1 and $6 \mathrm{mg} / \mathrm{kg}$ for subsequent cycles. Dose modifications of pertuzumab and trastuzumab were not permitted. Docetaxel was given at $75 \mathrm{mg} / \mathrm{m}^{2}$. Docetaxel dose escalation to $100 \mathrm{mg} / \mathrm{m}^{2}$ was allowed if tolerated; two docetaxel dose reductions by $25 \%$ to 75 or $55 \mathrm{mg} / \mathrm{m}^{2}$ were allowed in order to manage toxicities. Pertuzumab/placebo and trastuzumab were administered until investigator-assessed disease progression or unmanageable toxicity. At least six cycles of docetaxel were recommended; fewer cycles were allowed in the event of disease progression or unmanageable toxicity, more cycles at the discretion of the treating physician.

The study was conducted according to Good Clinical Practice and the Declaration of Helsinki. Protocol approval was obtained from an independent ethics committee at each participating site. All patients provided written informed consent.

\section{Patients}

Patients with HER2-positive (by central confirmation) locally recurrent, unresectable, or metastatic breast cancer who had not received prior chemotherapy or biological therapy for their advanced disease were eligible. Further inclusion criteria were measurable and/or non-measurable disease, a baseline left ventricular ejection fraction (LVEF) of at least $50 \%$, an Eastern Cooperative Oncology Group (ECOG) performance status [21] of 0 or 1, a disease-free interval of at least 12 months between completion of 
systemic treatment (excluding hormonal therapy) and diagnosis of metastatic disease, and a minimum age of 18 years. Exposure to trastuzumab during neoadjuvant and adjuvant therapy was allowed, as well as one hormonal treatment regimen for metastatic breast cancer before randomization. Among the exclusion criteria were treatment for metastatic breast cancer other than that described, metastases to the central nervous system, decline in LVEF to below $50 \%$ during or after prior therapy with trastuzumab, prior exposure to a cumulative dose of doxorubicin (or its equivalent) of more than $360 \mathrm{mg} / \mathrm{m}^{2}$, and history of congestive heart failure.

\section{Assessments}

Tumour assessments were based on RECIST and performed every 9 weeks. Adverse events were monitored continuously and graded according to the National Cancer Institute's Common Terminology Criteria for Adverse Events (NCI-CTCAE) v3.0. LVEF was assessed by echocardiography or multiple-gated acquisition scanning and the same method was to be used for an individual patient throughout the study. LVEF measurements took place at baseline, every 9 weeks during the treatment period, at the treatment discontinuation visit, every 6 months in the first year of follow-up, then annually for up to 3 years.

\section{Randomization and masking}

Patients were randomly assigned treatment in a 1:1 ratio. A complete block randomization scheme was applied in order to balance treatment assignment. Treatment allocation was stratified by geographic region (Asia, Europe, North America, and South America) and prior treatment status (neoadjuvant and/or adjuvant treatment received or not). An interactive voice response system was utilized to collect patient screening information and to allocate treatment. Patient identification numbers were allocated sequentially in the order in which patients were enrolled. The study was double-blinded.

\section{Statistical analyses}

A sample size of 800 patients was planned for the study and the primary analysis was defined to take place after 381 independently assessed progression-free survival events had occurred. With this number of events, it was estimated that the study had $80 \%$ power to detect a $33 \%$ improvement in median progression-free survival in the pertuzumab arm (hazard ratio [HR]: 0.75) at a two-sided significance level of $5 \%$. The log-rank test, with stratification according to prior treatment status and region, was used to compare independently assessed progression-free survival between both treatment arms. The Kaplan-Meier approach was used to estimate the median independently assessed progressionfree survival in each arm. A Cox proportional hazards model, with stratification according to prior treatment status and region, was used to estimate the hazard ratio and $95 \%$ confidence intervals (CIs). To analyze the consistency of the treatment effect, pre-specified subgroup analyses of progression-free survival were performed, including age groups ( $<65$, $\geq 65,<75$, and $\geq 75$ years). Adverse events were reported and analyzed using descriptive methods. The time to first event of left ventricular systolic dysfunction (LVSD) was evaluated by the Kaplan-Meier approach. A Cox regression analysis of time to first LVSD event was performed to investigate pre-defined potential risk factors for cardiac dysfunction, including age. SAS version 8.2 was used for statistical analyses. Efficacy analyses were performed according to treatment allocation (intention-to-treat [ITT] population) and safety analyses were performed as per treatment received.

The trial is registered with ClinicalTrials.gov, NCT00567190.

\section{Results}

\section{Study population}

In total, 808 patients were enrolled into the study from 204 sites in 25 countries; 406 patients were randomized to the placebo arm, 402 patients were randomized to the pertuzumab arm. In the ITT population, 681 patients $(84.3 \%)$ were younger than 65 years (339 in the placebo arm, 342 in the pertuzumab arm). There were 127 patients $(15.7 \%$ ) 65 years of age or older (67 in the placebo arm, 60 in the pertuzumab arm). Two patients in each arm did not receive any study treatment. Eight patients randomized to the placebo arm received at least one dose of pertuzumab. In the pertuzumab arm, one patient-received treatment allocated to the placebo arm only. The safety population therefore comprised 678 patients $<65$ years (placebo arm: 332; pertuzumab arm: 346 ) and 126 patients $\geq 65$ years (placebo arm: 65; pertuzumab arm: 61). The data cut-off for the analyses presented here took place in May 2011. Table 1 presents disease characteristics at baseline per age group. In both age groups, a higher proportion of patients randomized to the pertuzumab arm presented with ECOG performance status of 0 . In patients $\geq 65$ years, a higher proportion of patients randomized to the pertuzumab arm presented with nonvisceral disease. In the younger age group, $9.1 \%$ of patients in the placebo arm and $12.6 \%$ of patients in the pertuzumab arm had received neoadjuvant or adjuvant treatment with trastuzumab. For older patients, the proportion of patients with previous exposure to trastuzumab was $14.9 \%$ in the 
Table 1 Disease characteristics at baseline per age group

\begin{tabular}{|c|c|c|c|c|}
\hline \multirow[t]{2}{*}{$n(\%)$} & \multicolumn{2}{|l|}{$<65$ years } & \multicolumn{2}{|l|}{$\geq 65$ years } \\
\hline & $\begin{array}{l}\text { Placebo }+ \text { trastuzumab }+ \\
\text { docetaxel }(n=339)\end{array}$ & $\begin{array}{l}\text { Pertuzumab }+ \text { trastuzumab }+ \\
\text { docetaxel }(n=342)\end{array}$ & $\begin{array}{l}\text { Placebo }+ \text { trastuzumab }+ \\
\text { docetaxel }(n=67)\end{array}$ & $\begin{array}{l}\text { Pertuzumab }+ \text { trastuzumab }+ \\
\text { docetaxel }(n=60)\end{array}$ \\
\hline $\begin{array}{l}\text { Median age (range), } \\
\text { years }\end{array}$ & $51(27-64)$ & $53(22-64)$ & $68(65-89)$ & $69(65-82)$ \\
\hline \multicolumn{5}{|l|}{ ECOG PS } \\
\hline 0 & $208(61.4)$ & $235(68.7)$ & $40(59.7)$ & $39(65.0)$ \\
\hline 1 & $130(38.3)$ & $105(30.7)$ & $27(40.3)$ & $20(33.3)$ \\
\hline $2^{\mathrm{a}}$ & $0(0.0)$ & $2(0.6)$ & $0(0.0)$ & $1(1.7)$ \\
\hline $3^{\mathrm{a}}$ & $1(0.3)$ & $0(0.0)$ & $0(0.0)$ & $0(0.0)$ \\
\hline \multicolumn{5}{|l|}{ Disease type } \\
\hline Visceral disease & $261(77.0)$ & 269 (78.7) & $55(82.1)$ & $45(75.0)$ \\
\hline $\begin{array}{l}\text { Non-visceral } \\
\text { disease }\end{array}$ & $78(23.0)$ & $73(21.3)$ & $12(17.9)$ & $15(25.0)$ \\
\hline $\begin{array}{l}\text { Median number of } \\
\text { lesions (target and } \\
\text { non-target) }\end{array}$ & $5.0(1-19)$ & $5.0(1-17)$ & $4.0(1-16)$ & $4.0(1-17)$ \\
\hline Number of patients & 339 & 342 & 67 & 59 \\
\hline $\begin{array}{l}\text { Median measurable } \\
\text { tumour burden } \\
\text { (target lesions), } \\
\mathrm{mm}\end{array}$ & $79.0(10-455)$ & $79.0(10-422)$ & $79.0(13-365)$ & $82.5(10-404)$ \\
\hline Number of patients & 306 & 310 & 63 & 56 \\
\hline \multicolumn{5}{|l|}{$\begin{array}{l}\text { Hormone receptor } \\
\text { status }\end{array}$} \\
\hline $\begin{array}{l}\text { ER- and/or PgR- } \\
\text { positive }\end{array}$ & $172(50.7)$ & $158(46.2)$ & $27(40.3)$ & $31(51.7)$ \\
\hline $\begin{array}{l}\text { ER- and PgR- } \\
\text { negative }\end{array}$ & $159(46.9)$ & $183(53.5)$ & $37(55.2)$ & $29(48.3)$ \\
\hline Unknown & $8(2.4)$ & $1(0.3)$ & $3(4.5)$ & $0(0.0)$ \\
\hline \multicolumn{5}{|l|}{ HER2 status by IHC } \\
\hline 0 or $1+$ & $2(0.6)$ & $3(0.9)$ & $0(0.0)$ & $1(1.7)$ \\
\hline $2+$ & $26(7.7)$ & $38(11.1)$ & $6(9.0)$ & $9(15.0)$ \\
\hline $3+$ & $310(91.4)$ & $300(87.7)$ & $61(91.0)$ & $50(83.3)$ \\
\hline Unknown & $1(0.3)$ & $1(0.3)$ & $0(0.0)$ & $0(0.0)$ \\
\hline \multicolumn{5}{|l|}{$\begin{array}{l}\text { HER2 status by } \\
\text { FISH }\end{array}$} \\
\hline Positive & $320(94.4)$ & $326(95.3)$ & $63(94.0)$ & $58(96.7)$ \\
\hline Negative & $4(1.2)$ & $1(0.3)$ & $0(0.0)$ & $0(0.0)$ \\
\hline Unknown & $15(4.4)$ & $15(4.4)$ & $4(6.0)$ & $2(3.3)$ \\
\hline $\begin{array}{l}\text { Prior trastuzumab } \\
\text { treatment }\end{array}$ & $31(9.1)$ & $43(12.6)$ & $10(14.9)$ & $4(6.7)$ \\
\hline $\begin{array}{l}\text { Prior anthracycline } \\
\text { treatment }\end{array}$ & $140(41.3)$ & $135(39.5)$ & $24(35.8)$ & $15(25.0)$ \\
\hline Prior radiotherapy & 141 (41.6) & $146(42.7)$ & $34(50.7)$ & $25(41.7)$ \\
\hline $\begin{array}{l}\text { Median disease-free } \\
\text { interval }^{\mathrm{b}} \text {, months }\end{array}$ & $29.0(0-181)$ & $29.0(0-186)$ & $28.0(0-259)$ & $62.0(18-276)$ \\
\hline Number of patients & 156 & 153 & 31 & 20 \\
\hline
\end{tabular}

ECOG PS Eastern Cooperative Oncology Group performance status, ER estrogen receptor, FISH fluorescence in situ hybridization, IHC immunohistochemistry, $P g R$ progesterone receptor

${ }^{a}$ Protocol violation

${ }^{b}$ Defined as the period between completion of systemic treatment (excluding hormonal therapy) and diagnosis of metastatic disease 
placebo arm and $6.7 \%$ in the pertuzumab arm. A longer median disease-free interval, defined as the period between completion of systemic treatment (excluding hormonal therapy) and diagnosis of metastatic disease, was reported for patients $\geq 65$ years in the pertuzumab arm (62 months) compared with all other subgroups ( 28 or 29 months). In the study population, a higher proportion of older compared with younger patients reported previous (36.2 vs $28.2 \%$ ) and current $(85.8$ vs $66.7 \%)$ diseases other than breast cancer at baseline (Online Resource 1).

\section{Efficacy}

The analysis of independently assessed progression-free survival in the whole ITT population demonstrated a median progression-free survival of 12.4 months in the placebo arm and 18.5 months in the pertuzumab arm (HR: $0.62 ; 95 \%$ CI $0.51-0.75 ; P<0.0001$ ) [18]. Exploratory analyses of independently assessed progression-free survival by age group $(<65, \geq 65,<75$, and $\geq 75$ years) were pre-defined per protocol. The hazard ratios observed in all age groups were comparable to the hazard ratio in the whole ITT population, suggesting that the treatment benefit observed with pertuzumab is consistent in all analyzed age groups (Fig. 1a). The wide confidence intervals for the group of patients $\geq 75$ years are a consequence of the small sample size $(n=19)$. In a post hoc analysis, Kaplan-Meier estimates for median independently assessed progressionfree survival in patients $<65$ years and patients $\geq 65$ years were calculated (Fig. 1b). In patients younger than 65 years, the median progression-free survival was
12.5 months in the placebo arm and 17.2 months in the pertuzumab arm (HR: $0.65 ; 95 \%$ CI $0.53-0.80$ ). In patients 65 years of age or older, median progression-free survival was 10.4 months in the placebo arm and 21.6 months in the pertuzumab arm (HR, 0.52; $95 \%$ CI $0.31-0.86$ ) (Table 2).

The objective response rate (complete response plus partial response), assessed in patients with independently confirmed measurable disease at baseline, favored treatment in the pertuzumab arm in all age groups (Table 3 ). The difference in response rates was $10.8 \%$ points in the whole ITT population, $11.5 \%$ points in patients $<65$ years and $8.1 \%$ points in patients $\geq 65$ years. The analysis of objective response rate per age group was exploratory only.

\section{Exposure to docetaxel}

In all subgroups, at least $90 \%$ of patients who permanently discontinued docetaxel completed the recommended number of at least six cycles of docetaxel (Table 4). The proportion of patients who discontinued docetaxel due to an adverse event was generally balanced across subgroups, although a smaller proportion of patients $\geq 65$ years in the pertuzumab arm discontinued docetaxel due to an adverse event. The median number of docetaxel cycles was comparable between treatment arms but lower in older patients (6.5 and 6.0) compared with the subgroup of younger patients (8.0 in both arms). Docetaxel dose reductions below $75 \mathrm{mg} / \mathrm{m}^{2}$ occurred more often in patients 65 years of age or older than in younger patients, though this did not impact on median docetaxel dose intensity.
Fig. 1 Independently assessed progression-free survival per age group. a Hazard ratios and $95 \%$ confidence intervals for independently assessed progression-free survival in prespecified subgroups according to age. b Kaplan-Meier estimates of independently assessed progression-free survival in patients $<65$ years and patients $\geq 65$ years randomized to receive placebo, trastuzumab, and docetaxel or pertuzumab, trastuzumab, and docetaxel. $C I$ confidence interval, $H R$ hazard ratio, $D$ docetaxel, Pla placebo, Ptz pertuzumab, $T$ trastuzumab
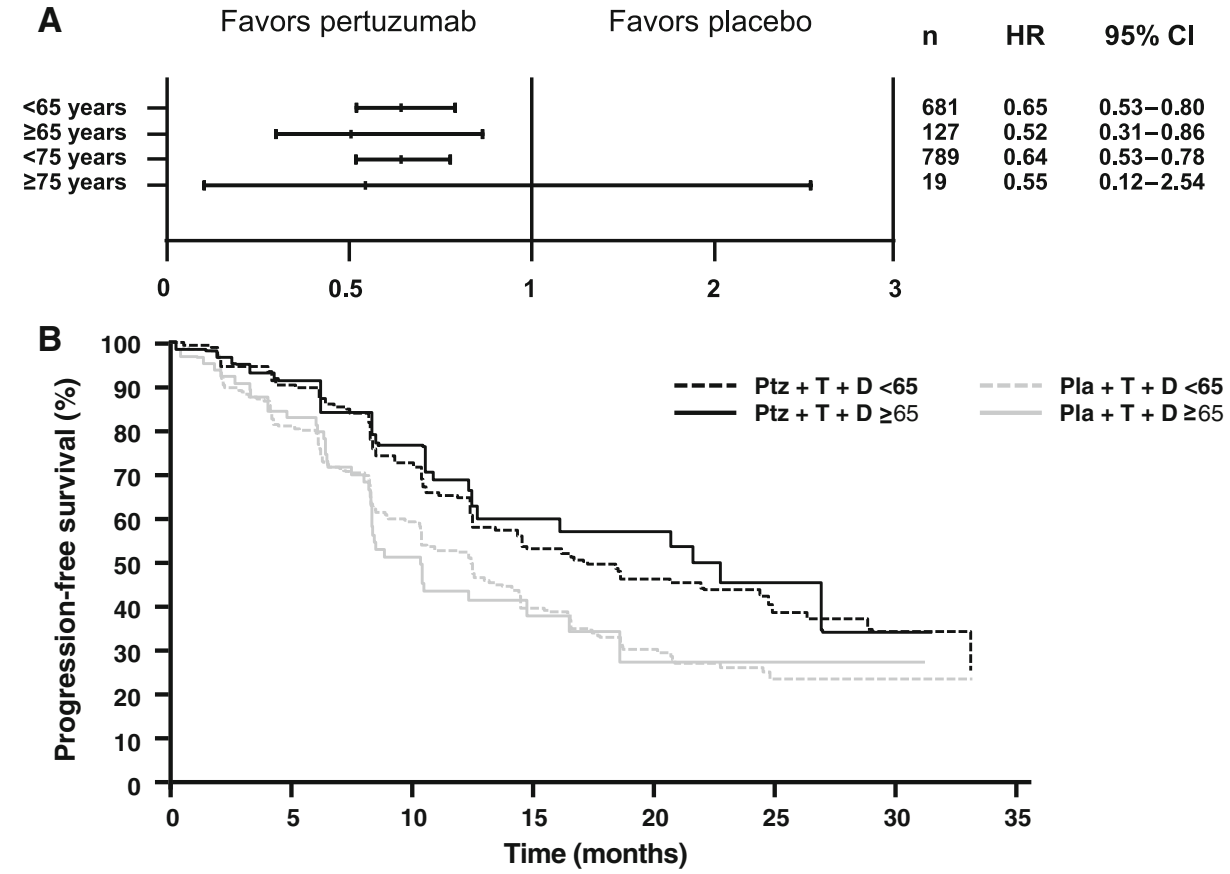
Table 2 Independently assessed progression-free survival in the whole study population and per age group

$C I$ confidence interval, $H R$ hazard ratio, $P F S$ progressionfree survival

Table 3 Independently assessed objective response rate in patients with measurable disease at baseline

$O R R$ objective response rate

\begin{tabular}{lll}
\hline & $\begin{array}{l}\text { Placebo }+ \text { trastuzumab }+ \\
\text { docetaxel }\end{array}$ & $\begin{array}{l}\text { Pertuzumab }+ \text { trastuzumab }+ \\
\text { docetaxel }\end{array}$ \\
\hline Whole study population, $n$ & 406 & 402 \\
Median PFS, months & 12.4 & 18.5 \\
HR $(95 \%$ CI) & $0.62(0.51-0.75)$ & 342 \\
Patients $<65$ years, $n$ & 339 & 17.2 \\
Median PFS, months & 12.5 & \\
HR $(95 \%$ CI) & $0.65(0.53-0.80)$ & 60 \\
Patients $\geq 65$ years, $n$ & 67 & 21.6 \\
Median PFS, months & 10.4 & \\
HR $(95 \%$ CI) & $0.52(0.31-0.86)$ & \\
\hline
\end{tabular}

\begin{tabular}{lll}
\hline & $\begin{array}{l}\text { Placebo }+ \text { trastuzumab }+ \\
\text { docetaxel }\end{array}$ & $\begin{array}{l}\text { Pertuzumab }+ \text { trastuzumab }+ \\
\text { docetaxel }\end{array}$ \\
\hline Whole study population, $n$ & 336 & 343 \\
ORR, $n(\%)$ & $233(69.3)$ & $275(80.2)$ \\
Patients $<65$ years, $n$ & $P=0.0011$ & 293 \\
ORR, $n(\%)$ & 278 & $233(79.5)$ \\
Patients $\geq 65$ years, $n$ & $189(68.0)$ & 50 \\
ORR, $n(\%)$ & 58 & $42(84.0)$ \\
\hline
\end{tabular}

\section{Adverse events}

In both age groups, the incidences of diarrhoea, neutropenia, and dysgeusia (all grades) were higher in the pertuzumab arm compared with the placebo arm (Table 5). Following the discontinuation of docetaxel, the incidence of adverse events fell considerably, with the exception of LVSD. In both age groups, diarrhoea, fatigue, and rash were reported more frequently in the pertuzumab arm than in the placebo arm following docetaxel discontinuation (Table 5). No episodes of febrile neutropenia were reported in any arm or age group after discontinuation of docetaxel. In patients 65 years of age or older, diarrhoea, fatigue, asthenia, decreased appetite, vomiting, and dysgeusia (all grades) were reported more frequently in both treatment arms compared with younger patients. Neutropenia, on the other hand, was reported less frequently in the older subgroup of patients.

Adverse events of grade $\geq 3$ reported more frequently in the pertuzumab arm in both age groups were febrile neutropenia (especially in the younger subgroup) and diarrhoea (especially in older patients) (Table 6). Although peripheral neuropathy (grade $\geq 3$ ) was reported with similar incidence for both arms in patients $<65$ years (six patients in each arm), its incidence was higher in patients $\geq 65$ years receiving treatment in the pertuzumab arm (five patients versus one patient). The incidences of diarrhoea and fatigue (grade $\geq 3$ ) were higher in older patients in both treatment arms compared with younger patients. In contrast, grade $\geq 3$ neutropenia, leukopenia, and febrile neutropenia were reported less frequently in older patients compared with the younger subgroup.

The proportion of patients who received medication with granulocyte-colony-stimulating factors (G-CSFs) was lower in the older subgroup compared with the younger subgroup. In patients less than 65 years of age, 114/332 $(34.3 \%)$ patients in the placebo arm and 135/346 (39.0\%) patients in the pertuzumab arm-received G-CSFs. For patients 65 years of age or older, 19/65 (29.2\%) patients received medication with G-CSFs in the placebo arm and $12 / 61(19.7 \%)$ patients received G-CSFs in the pertuzumab arm.

In a univariate Cox regression analysis, age had no statistically significant association with the development of asymptomatic or symptomatic LVSD ( $\geq 65$ years vs $<65$ years: HR: 1.25 ; $95 \%$ CI $0.61-2.56 ; P=0.5502$; $\geq 75$ years versus $<75$ years: HR: $2.25 ; 95 \%$ CI $0.55-9.29$; $P=0.2606$ ). Due to the low number of LVSD events overall $(n=51$; Table 5$)$, the analysis has limited sensitivity to detect differences in time to event by age group.

\section{Discussion}

We evaluated efficacy and safety of pertuzumab, trastuzumab, and docetaxel or placebo, trastuzumab, and docetaxel as first-line therapy for HER2-positive metastatic 
Table 4 Exposure to docetaxel treatment

\begin{tabular}{|c|c|c|c|c|}
\hline & \multicolumn{2}{|l|}{$<65$ years } & \multicolumn{2}{|l|}{$\geq 65$ years } \\
\hline & $\begin{array}{l}\text { Placebo }+ \text { trastuzumab }+ \\
\text { docetaxel }(n=332)\end{array}$ & $\begin{array}{l}\text { Pertuzumab }+ \text { trastuzumab }+ \\
\text { docetaxel }(n=346)\end{array}$ & $\begin{array}{l}\text { Placebo }+ \text { trastuzumab }+ \\
\text { docetaxel }(n=65)\end{array}$ & $\begin{array}{l}\text { Pertuzumab }+ \text { trastuzumab }+ \\
\text { docetaxel }(n=61)\end{array}$ \\
\hline $\begin{array}{l}\text { Median number } \\
\text { of cycles } \\
\text { administered } \\
\text { (range) }\end{array}$ & $8.0(1-41)$ & $8.0(1-35)$ & $6.5(1-26)$ & $6.0(1-16)$ \\
\hline $\begin{array}{l}\text { Median dose intensity, } \\
\mathrm{mg} / \mathrm{m}^{2} / \text { week }\end{array}$ & 24.8 & 24.5 & 24.8 & 24.8 \\
\hline $\begin{array}{l}\text { Dose escalation } \\
\text { to } 100 \mathrm{mg} / \mathrm{m}^{2}, \\
n(\%)\end{array}$ & $53(16.0)$ & $41(11.8)$ & $8(12.3)$ & $7(11.5)$ \\
\hline $\begin{array}{l}\text { Dose reduction to } \\
<75 \mathrm{mg} / \mathrm{m}^{2} \\
n(\%)\end{array}$ & $72(21.7)$ & 85 (24.6) & $17(26.2)$ & $19(31.1)$ \\
\hline \multicolumn{5}{|l|}{$\begin{array}{l}\text { Docetaxel } \\
\text { permanently } \\
\text { discontinued }\end{array}$} \\
\hline No, $n(\%)$ & $117(35.2)$ & $97(28.0)$ & $25(38.5)$ & $12(19.7)$ \\
\hline Yes, $n(\%)$ & $215(64.8)$ & $249(72.0)$ & $40(61.5)$ & $49(80.3)$ \\
\hline $\begin{array}{l}\geq 6 \text { cycles of } \\
\text { docetaxel } \\
\text { completed, } \\
n / N(\%)\end{array}$ & 209/215 (97.2) & 238/249 (95.6) & $36 / 40(90.0)$ & 47/49 (95.9) \\
\hline \multicolumn{5}{|l|}{$\begin{array}{l}\text { Reason for } \\
\text { discontinuation, } \\
n / N(\%)\end{array}$} \\
\hline Standard practice & $127 / 215(59.1)$ & $140 / 249(56.2)$ & $22 / 40(55.0)$ & $37 / 49(75.5)$ \\
\hline Adverse event & $75 / 215$ (34.9) & $85 / 249(34.1)$ & $15 / 40(37.5)$ & $12 / 49(24.5)$ \\
\hline $\begin{array}{l}\text { Refused } \\
\text { treatment }\end{array}$ & $6 / 215(2.8)$ & $12 / 249(4.8)$ & $1 / 40(2.5)$ & $0 / 49(0.0)$ \\
\hline Other & $7 / 215$ (3.3) & $12 / 249(4.8)$ & $2 / 40(5.0)$ & $0 / 49(0.0)$ \\
\hline
\end{tabular}

breast cancer in patients $\geq 65$ years compared with patients $<65$ years. Treatment with pertuzumab, trastuzumab, and docetaxel resulted in superior progression-free survival in both age groups compared with the placebo arm. The longmedian progression-free survival of 21.6 months reported in patients $\geq 65$ years in the pertuzumab arm may be based on some favourable disease characteristics observed in this subgroup, such as a lower proportion of patients with previous exposure to trastuzumab, a higher proportion of patients with non-visceral disease and a longer median disease-free interval, characteristics that suggest more indolent disease in these patients. However, the small sample size limits the interpretation of these observations. A higher incidence of grade $\geq 3$ diarrhoea was reported in older patients treated in the pertuzumab arm, and so patients receiving this regimen should be closely monitored in clinical practice. The dose of docetaxel was reduced more frequently and the median number of docetaxel cycles was lower (6.5 and 6.0 cycles per arm) in older patients, which probably explains the lower incidence of neutropenia and febrile neutropenia, as well as less frequent use of G-CSFs. These observations suggest that toxicities were more often managed by docetaxel dose adjustments in patients $\geq 65$ years than in younger patients. Nevertheless, the median number of docetaxel cycles administered in older patients complies with the per-protocol recommendation of at least six cycles, and $\geq 90 \%$ of patients who permanently discontinued docetaxel had received at least six cycles of docetaxel. It is interesting to note that, despite more frequent docetaxel dose reductions and a lower median number of docetaxel cycles, the overall efficacy outcomes of older patients were similar to those of younger patients, which raises the question about the optimal duration of chemotherapy when it is combined with HER2-targeted treatment.

The combination of pertuzumab with trastuzumab in CLEOPATRA did not increase the risk of cardiac dysfunction associated with trastuzumab [22], and there was no 


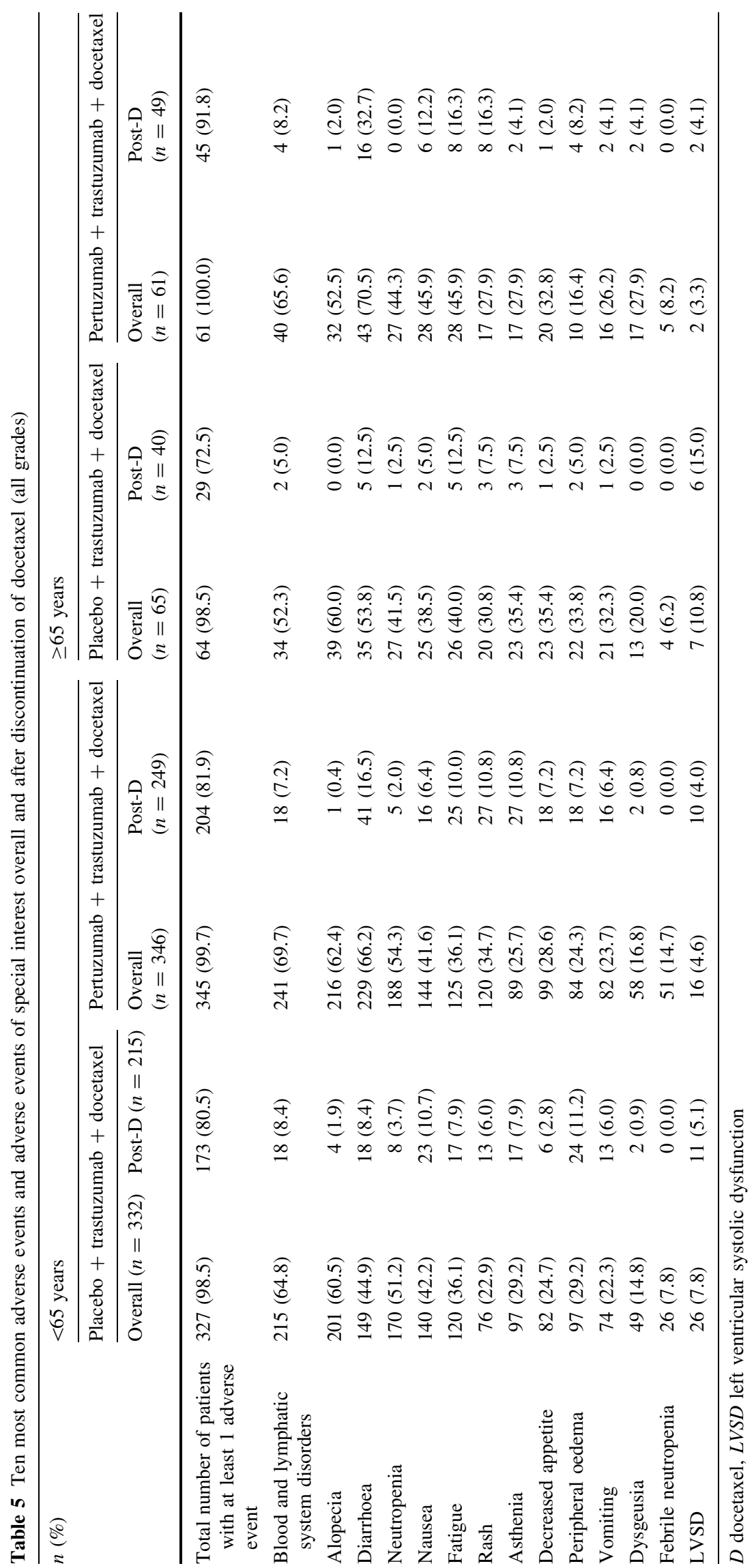


Table 6 Ten most common grade $\geq 3$ adverse events overall

\begin{tabular}{|c|c|c|c|c|}
\hline \multirow[t]{2}{*}{$n(\%)$} & \multicolumn{2}{|l|}{$<65$ years } & \multicolumn{2}{|l|}{$\geq 65$ years } \\
\hline & $\begin{array}{l}\text { Placebo }+ \text { trastuzumab }+ \\
\text { docetaxel }(n=332)\end{array}$ & $\begin{array}{l}\text { Pertuzumab }+ \text { trastuzumab }+ \\
\text { docetaxel }(n=346)\end{array}$ & $\begin{array}{l}\text { Placebo }+ \text { trastuzumab }+ \\
\text { docetaxel }(n=65)\end{array}$ & $\begin{array}{l}\text { Pertuzumab }+ \text { trastuzumab }+ \\
\text { docetaxel }(n=61)\end{array}$ \\
\hline $\begin{array}{l}\text { Total number of } \\
\text { patients with at } \\
\text { least one } \\
\text { grade } \geq 3 \\
\text { adverse event }\end{array}$ & 241 (72.6) & 255 (73.7) & $48(73.8)$ & $47(77.0)$ \\
\hline $\begin{array}{l}\text { Blood and } \\
\text { lymphatic } \\
\text { system } \\
\text { disorders }\end{array}$ & $184(55.4)$ & $210(60.7)$ & $31(47.7)$ & $30(49.2)$ \\
\hline Neutropenia & $156(47.0)$ & $174(50.3)$ & $26(40.0)$ & $25(41.0)$ \\
\hline Leukopenia & $51(15.4)$ & $44(12.7)$ & 7 (10.8) & $6(9.8)$ \\
\hline $\begin{array}{l}\text { Febrile } \\
\text { neutropenia }\end{array}$ & $26(7.8)$ & $51(14.7)$ & $4(6.2)$ & $5(8.2)$ \\
\hline Diarrhoea & $16(4.8)$ & $23(6.6)$ & $4(6.2)$ & $9(14.8)$ \\
\hline Anaemia & $9(2.7)$ & $10(2.9)$ & $5(7.7)$ & $0(0.0)$ \\
\hline Fatigue & $9(2.7)$ & $7(2.0)$ & $4(6.2)$ & $2(3.3)$ \\
\hline $\begin{array}{l}\text { Peripheral } \\
\text { neuropathy }\end{array}$ & $6(1.8)$ & $6(1.7)$ & $1(1.5)$ & $5(8.2)$ \\
\hline LVSD & $8(2.4)$ & $4(1.2)$ & $3(4.6)$ & 1 (1.6) \\
\hline Asthenia & $4(1.2)$ & $10(2.9)$ & $2(3.1)$ & $0(0.0)$ \\
\hline Granulocytopenia & $9(2.7)$ & $4(1.2)$ & $0(0.0)$ & $2(3.3)$ \\
\hline
\end{tabular}

LVSD left ventricular systolic dysfunction

evidence of late or cumulative cardiac toxicity after an additional year of follow-up [19]. Although older patients are at increased risk of congestive heart failure, we could not find a significant correlation of age with the development of asymptomatic or symptomatic LVSD. Nevertheless, routine monitoring of cardiac function in patients receiving trastuzumab and pertuzumab is recommended.

Due to the increase in life expectancy, the number of older patients with breast cancer will rise and treatment decisions should be based on an acceptable benefit-risk ratio. According to data from 2011 in the US, women aged 65-69 and 70-74 years have a life expectancy of about 20 and 16 years, respectively [23]. Underestimation of a patient's life expectancy and of their general physical ability may result in erroneous decisions to treat less aggressively, exposing the patient to an unnecessary risk of breast cancer-related death. However, the higher frequency of co-morbidities, mainly hypertension, arthritis, and heart diseases [7], in older patients with breast cancer is an equally important consideration for disease management. Studies have shown that older patients derive a similar benefit from chemotherapy to younger patients [24-26], but that they are more vulnerable to chemotherapy-related toxicities [24, 27, 28]. In their updated recommendations for the management of elderly patients with breast cancer the International Society of Geriatric Oncology (SIOG) and European Society of Breast Cancer Specialists (EUSOMA) emphasize that chronological age alone should not be a determinant for the treatment of breast cancer [29]. Decisions regarding treatment should rather be based on physiological age (fitness), estimated life expectancy, risks, benefits, treatment tolerance, patient preference, and potential treatment barriers [29]. In addition, an (abbreviated) comprehensive geriatric assessment may help guide informed treatment decisions for older patients with breast cancer [29].

Based on the efficacy benefit and the adverse events profile observed in CLEOPATRA, we suggest that the use of pertuzumab, trastuzumab, and docetaxel should not be limited by age, though proactive management of toxicities and regular cardiac monitoring should clearly be undertaken. At present, population-based data with the combination of pertuzumab and trastuzumab are limited due to its very recent approval. More evidence on the tolerability and efficacy of pertuzumab and trastuzumab in HER2-positive metastatic breast cancer in combination with different chemotherapy partners and aromatase inhibitors in patients with hormone receptor-positive disease will be obtained in several clinical trials currently ongoing (NCT01572038, NCT01026142, NCT01565083, NCT01491737). 
Acknowledgments The study was funded by F. Hoffmann-La Roche Ltd (Basel, Switzerland) and by Genentech Inc. (South San Francisco, CA, USA), a member of the Roche group. Targos Molecular Pathology (Kassel, Germany) performed central HER2 testing. Funding for third-party writing assistance, furnished by Vilma Graupner, PhD, CMPP, was provided by F. Hoffmann-La Roche.

Open Access This article is distributed under the terms of the Creative Commons Attribution Noncommercial License which permits any noncommercial use, distribution, and reproduction in any medium, provided the original author(s) and the source are credited.

\section{References}

1. Siegel R, Naishadham D, Jemal A (2013) Cancer statistics, 2013. CA Cancer J Clin 63:11-30

2. Smith BD, Smith GL, Hurria A, Hortobagyi GN, Buchholz TA (2009) Future of cancer incidence in the United States: burdens upon an aging, changing nation. J Clin Oncol 27:2758-2765

3. Thun MJ, DeLancey JO, Center MM, Jemal A, Ward EM (2010) The global burden of cancer: priorities for prevention. Carcinogenesis 31:100-110

4. Hutchins LF, Unger JM, Crowley JJ, Coltman CA Jr, Albain KS (1999) Underrepresentation of patients 65 years of age or older in cancer-treatment trials. N Engl J Med 341:2061-2067

5. Louwman WJ, Janssen-Heijnen ML, Houterman S, Voogd AC, van der Sangen MJ, Nieuwenhuijzen GA, Coebergh JW (2005) Less extensive treatment and inferior prognosis for breast cancer patient with comorbidity: a population-based study. Eur J Cancer 41:779-785

6. Yancik R (1997) Cancer burden in the aged: an epidemiologic and demographic overview. Cancer 80:1273-1283

7. Yancik R, Wesley MN, Ries LA, Havlik RJ, Edwards BK, Yates JW (2001) Effect of age and comorbidity in postmenopausal breast cancer patients aged 55 years and older. JAMA 285:885-892

8. Kanapuru B, Ershler WB, Hesdorffer C, Jemal A, Yates JW (2012) Long-term survival of older breast cancer patients: population-based estimates over three decades. Breast Cancer Res Treat 134:853-857

9. Enger SM, Thwin SS, Buist DS, Field T, Frost F, Geiger AM, Lash TL, Prout M, Yood MU, Wei F, Silliman RA (2006) Breast cancer treatment of older women in integrated health care settings. J Clin Oncol 24:4377-4383

10. Ballard-Barbash R, Potosky AL, Harlan LC, Nayfield SG, Kessler LG (1996) Factors associated with surgical and radiation therapy for early stage breast cancer in older women. J Natl Cancer Inst 88:716-726

11. Giordano SH, Hortobagyi GN, Kau SW, Theriault RL, Bondy ML (2005) Breast cancer treatment guidelines in older women. J Clin Oncol 23:783-791

12. Bouchardy C, Rapiti E, Fioretta G, Laissue P, Neyroud-Caspar I, Schafer P, Kurtz J, Sappino AP, Vlastos G (2003) Undertreatment strongly decreases prognosis of breast cancer in elderly women. J Clin Oncol 21:3580-3587

13. Yood MU, Owusu C, Buist DS, Geiger AM, Field TS, Thwin SS, Lash TL, Prout MN, Wei F, Quinn VP, Frost FJ, Silliman RA (2008) Mortality impact of less-than-standard therapy in older breast cancer patients. J Am Coll Surg 206:66-75

14. Kaufman PA, Brufsky AM, Mayer M, Rugo HS, Tripathy D, Yood MU, Feng S, Wang LI, Quah CS, Yardley DA (2012) Treatment patterns and clinical outcomes in elderly patients with
HER2-positive metastatic breast cancer from the registHER observational study. Breast Cancer Res Treat 135:875-883

15. Piccart-Gebhart MJ, Procter M, Leyland-Jones B, Goldhirsch A, Untch M, Smith I, Gianni L, Baselga J, Bell R, Jackisch C, Cameron D, Dowsett M, Barrios CH, Steger G, Huang CS, Andersson M, Inbar M, Lichinitser M, Lang I, Nitz U, Iwata H, Thomssen C, Lohrisch C, Suter TM, Ruschoff J, Suto T, Greatorex V, Ward C, Straehle C, McFadden E, Dolci MS, Gelber RD (2005) Trastuzumab after adjuvant chemotherapy in HER2positive breast cancer. N Engl J Med 353:1659-1672

16. Smith I, Procter M, Gelber RD, Guillaume S, Feyereislova A, Dowsett M, Goldhirsch A, Untch M, Mariani G, Baselga J, Kaufmann M, Cameron D, Bell R, Bergh J, Coleman R, Wardley A, Harbeck N, Lopez RI, Mallmann P, Gelmon K, Wilcken N, Wist E, Sanchez RP, Piccart-Gebhart MJ (2007) 2-year follow-up of trastuzumab after adjuvant chemotherapy in HER2-positive breast cancer: a randomised controlled trial. Lancet 369:29-36

17. Partridge AH, Gelber S, Piccart-Gebhart MJ, Focant F, Scullion M, Holmes E, Winer EP, Gelber RD (2013) Effect of age on breast cancer outcomes in women with human epidermal growth factor receptor 2-positive breast cancer: results from a Herceptin adjuvant trial. J Clin Oncol 31:2692-2698

18. Baselga J, Cortes J, Kim SB, Im SA, Hegg R, Im YH, Roman L, Pedrini JL, Pienkowski T, Knott A, Clark E, Benyunes MC, Ross G, Swain SM (2012) Pertuzumab plus trastuzumab plus docetaxel for metastatic breast cancer. N Engl J Med 366:109-119

19. Swain SM, Kim SB, Cortes J, Ro J, Semiglazov V, Campone M, Ciruelos E, Ferrero JM, Schneeweiss A, Knott A, Clark E, Ross G, Benyunes MC, Baselga J (2013) Pertuzumab, trastuzumab, and docetaxel for HER2-positive metastatic breast cancer (CLEOPATRA study): overall survival results from a randomised, doubleblind, placebo-controlled, phase 3 study. Lancet Oncol 14:461-471

20. Therasse P, Arbuck SG, Eisenhauer EA, Wanders J, Kaplan RS, Rubinstein L, Verweij J, Van Glabbeke M, van Oosterom AT, Christian MC, Gwyther SG (2000) New guidelines to evaluate the response to treatment in solid tumors. European Organization for Research and Treatment of Cancer, National Cancer Institute of the United States, National Cancer Institute of Canada. J Natl Cancer Inst 92:205-216

21. Oken MM, Creech RH, Tormey DC, Horton J, Davis TE, McFadden ET, Carbone PP (1982) Toxicity and response criteria of the Eastern Cooperative Oncology Group. Am J Clin Oncol 5:649-655

22. Swain SM, Ewer MS, Cortes J, Amadori D, Miles D, Knott A, Clark E, Benyunes MC, Ross G, Baselga J (2013) Cardiac tolerability of pertuzumab plus trastuzumab plus docetaxel in patients with HER2-positive metastatic breast cancer in CLEOPATRA: a randomized, double-blind, placebo-controlled phase III study. Oncologist 18:257-264

23. World Health Organization. Global Health Observatory Data Repository. 2013

24. Muss HB, Woolf S, Berry D, Cirrincione C, Weiss RB, Budman D, Wood WC, Henderson IC, Hudis C, Winer E, Cohen H, Wheeler J, Norton L (2005) Adjuvant chemotherapy in older and younger women with lymph node-positive breast cancer. JAMA 293:1073-1081

25. Gelman RS, Taylor SG (1984) Cyclophosphamide, methotrexate, and 5 -fluorouracil chemotherapy in women more than 65 years old with advanced breast cancer: the elimination of age trends in toxicity by using doses based on creatinine clearance. J Clin Oncol 2:1404-1413

26. Christman K, Muss HB, Case LD, Stanley V (1992) Chemotherapy of metastatic breast cancer in the elderly. The Piedmont Oncology Association experience [see comment]. JAMA 268:57-62

27. Du XL, Osborne C, Goodwin JS (2002) Population-based assessment of hospitalizations for toxicity from chemotherapy in older women with breast cancer. J Clin Oncol 20:4636-4642 
28. Crivellari D, Bonetti M, Castiglione-Gertsch M, Gelber RD, Rudenstam CM, Thurlimann B, Price KN, Coates AS, Hurny C, Bernhard J, Lindtner J, Collins J, Senn HJ, Cavalli F, Forbes J, Gudgeon A, Simoncini E, Cortes-Funes H, Veronesi A, Fey M, Goldhirsch A (2000) Burdens and benefits of adjuvant cyclophosphamide, methotrexate, and fluorouracil and tamoxifen for elderly patients with breast cancer: The International Breast Cancer Study Group Trial VII. J Clin Oncol 18:1412-1422
29. Biganzoli L, Wildiers H, Oakman C, Marotti L, Loibl S, Kunkler I, Reed M, Ciatto S, Voogd AC, Brain E, Cutuli B, Terret C, Gosney M, Aapro M, Audisio R (2012) Management of elderly patients with breast cancer: updated recommendations of the International Society of Geriatric Oncology (SIOG) and European Society of Breast Cancer Specialists (EUSOMA). Lancet Oncol 13:e148-e160 